\title{
Towards a More Connected Field of Community Development Education: Encouraging Community Well-Being Through an Engaged Symposium
}

\author{
Virginia Stanard ${ }^{1} \cdot$ Kristina D. Hains $^{2}$ (D) Neil A. Knobloch ${ }^{3} \cdot$ Ceara O'Leary $^{1}$. \\ Addie Reinhard ${ }^{4} \cdot$ Bryan J. Hains $^{2} \cdot$ Michael Rios $^{5}$
}

Received: 9 November 2020 / Accepted: 2 March 2021 / Published online: 30 March 2021

(c) The Author(s), under exclusive licence to Springer Nature Switzerland AG 2021

\begin{abstract}
As society continues to shift and progress, the field of community development becomes more salient to the well-being and sustainability of rural and urban communities. Globalization, global pandemics, technological change, and devolution are among several issues impacting the well-being of rural townships and urban neighborhoods nationally and globally. Post-secondary community development degree programs may be vital in developing individuals to address these unique issues. However, due to the multidisciplinary nature of the field, there has been a lack of communication and consensus among educators regarding the necessary skills, theories, and practices to teach in these programs. In 2017, a foundational initiative was implemented to examine community development education higher education programs across the United States. A unique component of this initiative was the inaugural Community Development Education Symposium. This innovative symposium engaged many community development educators from a variety of fields in an intense, purposeful three day event. This article captures the synergy of bringing together community development educators in a uniquely structured symposium, to network, share expertise, and ultimately build a Community of Practice (CoP) towards a more connected field of community development education and ultimately enhancing the well-being of communities through their student graduates.
\end{abstract}

Keywords Symposium · Community development · Community development education · Higher education · Community of Practice (CoP)

Kristina D. Hains

k.hains@uky.edu

Extended author information available on the last page of the article 


\section{Introduction}

When reflecting on our current society, it is easy to surmise that the well-being of our communities is consistently impacted by health and social unrest (Kraeger et al., 2017). Globalization, global pandemics, technological change, and devolution are among several issues impacting the livelihoods of rural townships and urban neighborhoods around the world. As such, it can be argued that the field of community development becomes even more pertinent to the health and sustainability of rural and urban communities (Lee et al., 2015).

Specific to rural America, these phenomena have become so prominent that the United States Department of Agriculture (U.S.D.A) has chosen revitalization of rural communities as one of its primary goals. In it's 2014-18 strategic plan, U.S.D.A identified Goal 1: "Assist(ing) rural communities to create prosperity so that they are self-sustaining, repopulating, and economically thriving" (United States Department of Agriculture, 2014) as a primary initiative. This governmental initiative clearly highlights the need for community development professionals to assist in enhancing the economic, social and psychological well-being of these communities (Phillips \& Lee, 2018); however, due to limited knowledge of current programmatic structures, curriculum and instructional methods, there is an urgent need to investigate the current status of community development higher education.

Over the last few decades, the field of community development has grown substantially, creating a need for further professional training and development. Today, there are over 80 graduate and undergraduate community development programs across the United States (Hains et al., 2021). While this growth is often viewed as positive, community development education, nationally, remains splintered. Educational standards, core content, and teaching practices have not been identified or agreed upon by educators - who span diverse disciplines and community contexts. Additionally, there is lack of communication among community development educators regarding the current state of the discipline, what new knowledge and methods are emerging, and where the field is going. In response, our goal was to facilitate professional conversations of current pedagogy to be relevant to the training of future practitioners and ultimately enhance the community-well-being for the communities in which they live and work.

Gruidl and Hustedde (2015) contended that educators in U.S. post-secondary community development degree programs have not communicated with each other about the relevant theory, skill development, pedagogical approaches, and educational standards necessary for effective community development education across the rural and urban interface. The splintering of the field is compounded by its multidisciplinary nature - because community development is a process, it transcends diverse community contexts, an aspect often not realized when trained in a traditional discipline. However, it was speculated that should community development educators convene to discuss such topics, a synergistic movement would emerge transforming community development education, resulting in a more diverse student workforce and benefitting the well-being of domestic and international communities.

Fast forward to 2017, where a foundational initiative to identify and describe university based community development education programs across the United States 
was commenced. The initiative was prompted by research signifying a vast professional divide among community development educators and programs nationally. Due to its multidisciplinary nature, community development educators are often displaced amongst various disciplinary professional organizations. These organizations occasionally highlight aspects of university-based community development education, but it is often not their primary focus. As such, it could be argued that the fundamental well-being of this community of practice "community development educators" was marginal due to its lack of access, solidarity and capacity. Community well-being can be defined as the combination of social, economic, cultural and political conditions that individuals and communities identify as necessary for them to reach their full potential (Wiseman \& Brasher, 2008). Within this case, the social and cultural need for community development educators to engage in pedagogical dialogue was evident. Additionally, the political and economic conditions were such that community development programs across the United States were growing, further indicating the need for collegial discussion and collaboration. Lastly, the ripple effect of networking and sharing instructional practices could have direct implications on the future community leaders or students from each of the community development programs.

A primary result of the overall initiative was to identify the skills and knowledge foundational to community development education, as well as facilitate national communication on best practices, curriculum and program development, and student inclusion (Hains et al., 2021). To assist with this, a particularly unique event was designed - the Community Development Education Symposium that was held in Detroit, Michigan during May 2019. This symposium was especially innovative in that it engaged many community development educators from a variety of fields in an engaging, intense and purposeful three-day event. Thus, the purpose of this case article is to describe the unique synergy of bringing together university based community development educators as they participated in an innovative symposium to establish a Community of Practice (CoP), further shaping the field of community development education and enhancing the community's professional well-being.

\section{Innovation within Academic Conferences}

Academic conferences and symposia are standard events across academic disciplines. These functions are considered vital for dissemination of research, networking, and learning. Disciplines have standard ways of conducting conferences, but are these standards best practices to optimize networking, learning, and sharing research? These events are deemed important within academia; yet, there is little published research on the effectiveness of academic conferences in satisfying these needs. Some researchers have begun to question the traditional way of conducting an academic conference. Rom (2012), a political science scholar from Georgetown University, suggested an overhaul to the conventional political science conference by instating a "Customized Conference" approach that builds scholarly community and meets individual preferences of participants. In response to Rom, Deardorff (2015) agreed that political sciences 
conferences should reconsider their structure stressing the importance of networking and community building at conferences as many faculty working in small departments can become intellectually isolated. Scholars from other disciplines have also questioned the traditional conference model. Castronova (2013) suggested dropping conventional sessions completely and created an entire conference by conducting a formal social gathering by using games to encourage networking and sharing of ideas.

Engagement within conferences and symposia has become an important focus. Researchers have used technology to enhance community engagement during conferences with varying success (Levy et al., 2016; McCarthy et al., 2004). A recent International Applied Anthropology Symposium incorporated panel-discussions, speed-talks, workshops, and social events to encourage engagement through sharing of information, experiences, and discussions (Korčulanin \& Meal, 2018). The Pecha Kucha, "lightning talk", format was used for speed-talk presentations during this anthropology symposium. This method limits presenters to 20 slides each displayed for $20 \mathrm{~s}$ and has been shown to be equally effective as traditional PowerPoint lectures as a learning tool with no significant difference in assessment scores between the two methods (Klentzin et al., 2010).

Other scholars are utilizing distance techniques or conducting "unconferences" to stimulate more creativity and connection. Unconferences reject conventional planned conference structure and adopt a flexible structure allowing participant driven ideas and discussion without a specific agenda (Hale \& Bessette, 2016). Sawhney (2013) critiqued unconferences by suggesting that we should not depart from the organized nature of the conventional conference but instead, seek to find new ways to combine the formal elements of the conventional conference (structure in activities) and informal elements of the unconference (participant-driven) to produce a creative environment. What's more, within the unique environment created in 2020 with the appearance of COVID-19, many conferences switched to a completely online format. Associations such as the American Association for Agricultural Education (AAAE) and Environmental Design Research Association (EDRA) chose to engage their audiences in their annual conferences utilizing distance techniques, rather than forgo any interaction due to the unique circumstances presented. The bottom line is that while many variations of the conventional conference model have been suggested, little evaluative work has been done to assess the efficacy of these variations. This article aims to describe the unique and innovative aspects of the Community Development Education Symposium providing evaluative data to support the use of these unique innovations among future academic conferences and symposia.

\section{Methodology}

\section{Building an Engaged Symposium}

To build social capital and bring together educators from across the United States, a symposium that focused on Community Development Higher Education was held 
in Detroit, Michigan in the spring of 2019. From its inception, the event was framed as a "symposium" rather than a "conference" to privilege dialogue, discussion, and exchange through various joint activities. In developing this innovative approach to information sharing and networking, the collaborative, multi-university and disciplinary team of organizers drew on best practices and lessons learned from events they had attended. The goal was to create an inclusive experience where participants would be together for the majority of symposium. Further, multiple venues were utilized to foster this inclusive environment, from an outdoor courtyard at a neighborhood-based hotel where participants stayed, to a local Hispanic community development corporation, to the campus of the host university. Each venue provided participants a renewed opportunity to build community while introducing them to Detroit's neighborhoods and community development culture. The result was a collection of unconventional tactics, activities, and settings that supported the creation of a new community of practice among community development educators.

\section{Symposium Overview}

The inaugural 2019 Community Development Education Symposium focused on community development education and educational delivery for undergraduate and graduate students. The symposium brought together a diverse group of 70 community development educators from over 20 universities to share knowledge, best practices, and innovative ideas for teaching and learning. Specifically, the symposium showcased community development programs and curricula, educational methods, and student and professional development that advance the impact of community development education by probing:

- What is shifting in community development education?

- Where is knowledge emerging?

- Are there new models for community development education?

- What changes in the community development field inform education?

- What are innovative methods for teaching and learning community development?

These questions were explored through an unconventional format of joint activities including raconteur panels and reflections, story circles, conversation exchanges, lightning talks, world café roundtables, and dine arounds, as described below.

\section{Raconteur Panels and Reflections}

Raconteur is French for an individual who is skilled in relating stories and anecdotes. Due to the innovative symposium design, particularly focused on different fields' experiences, stories, and reflections, a raconteur panel was fashioned. Four raconteur discussants served to frame the discourse and provide thought leadership throughout the symposium. In this role, the raconteurs facilitated an opening panel on "Challenging Community Development Education," responded to presentations and discussions, and provided closing reflections on the overall symposium. Selected because of their leadership and experience in community development 
education, the raconteurs represented disciplines of sociology, agriculture and life sciences, urban planning, architecture, and economic development. As such, they were invaluable in framing the issues from a multidisciplinary lens as well as posing challenging questions to symposium participants. They also offered interesting stories, anecdotes, and humor in relation to community development education and symposium topics which served to stitch together the community of educators in big and small ways throughout the symposium.

\section{Ice Breaker Story Circle}

Following the opening panel, the Ice Breaker Story Circle started the conversation among participants by exploring the challenges that educators are facing in their community development education experiences. As outlined by the Working Narratives (n.d.) organization, a story circle is a group of individuals sitting in a circle and sharing their experiences regarding a specific theme or topic. Often this is utilized to build community within a group - especially important when pulling together individuals from diverse professions or fields. For this exercise, the group of participants sat in a circle or at picnic tables in an outdoor courtyard and shared stories about their experience in community development education. Specifically, the question, "Describe a challenge that you have you experienced as a community development educator," prompted a range of responses, from questioning the authenticity of community-university partnerships to finding a place within the broad, multidisciplinary field. The activity began the process of building community among the educators.

\section{Conversation Exchanges}

The Conversation Exchanges comprised the majority of the symposium. These peerreviewed, topical exchanges were geared toward sharing ideas, projects, and discussion around a community development education theme. The themes included "Community Engagement \& Higher Education," "Curriculum Development \& Student Skills," "Power \& Social Justice in Community Development Education," "International Applications in Community Development Education," and "Community Development Education through Multiple Lenses." Each themed exchange included one to three topics and one to four presenters. The format for each exchange included a brief introduction by a facilitator, an $8-10$ min presentation by each panel group, and a 45-min facilitated discussion among the panelists and symposium participants. Consistent questions were posed across themes to jumpstart the exchanges: "What were the successes you have experienced within your program [in relation to the theme]?" and "What have been the challenges you have experienced within your program [in relation to the theme]?"

Symposium participants then added to the discussion with additional contextual questions prompting inquisitive, lively, and at times, critical discussions. Because all of the symposium participants took part in each conversation exchange, as opposed to conferences where participants split up and attend concurrent sessions, the 
exchanges built upon and informed one another cultivating shared knowledge and community among the educators (Picture 1).

\section{Lightning Talks}

The Lightning Talks highlighted innovative methods in community development education in the format of short, thought-provoking peer-reviewed presentations. Each presentation was allowed 20 slides in $5 \mathrm{~min}$, and slides advanced automatically at fixed intervals. The goal of the lightning talk format was to articulate an innovative teaching method in a quick, concise, and insightful manner in order to capture the attention of the symposium participants. A few examples of topics discussed during the Lightning Talks included "Dark Community Development \& Critical Analysis," "Integrating Community Development Practitioners into the Classroom," and "D-Tour: Student Critical Self-Reflection Implicit Bias." Because several speakers presented their ideas in a single session, the symposium participants gained a broad array of shared knowledge on a variety of teaching methods.

\section{World Café Roundtables}

The World Café Roundtables were multiple, small group conversations around two focused themes: "Community Development Program Overviews and Pedagogy," of which there were seven distinct conversation topics, and "Core Competencies, Skills, and Knowledge" which included five topics. In order to provide a multiplicity of relevant topics, this was the singular activity at the symposium that was not

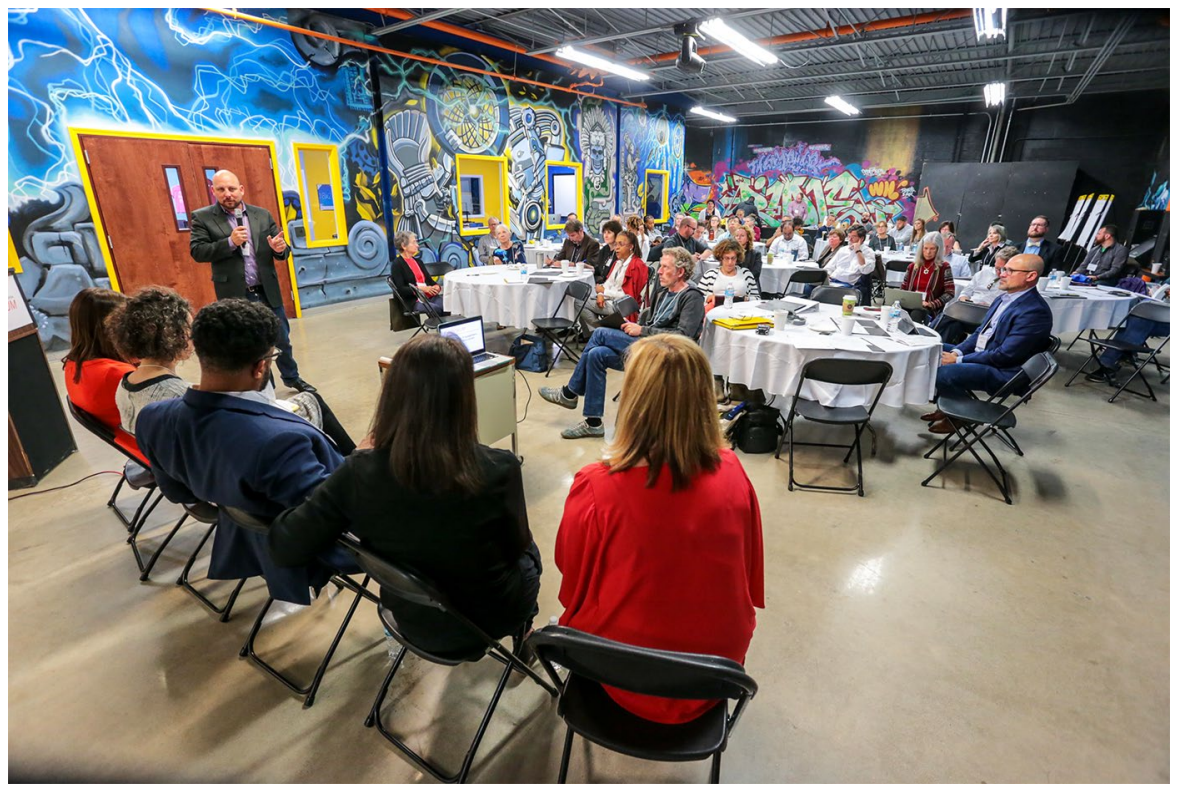

Picture 1 Expert Panel presenting during Conversation Exchange 
structured for inclusive participation. Rather, each roundtable was comprised of approximately 8-12 participants, a presenter, and facilitator/table host. The presenter gave a short peer-reviewed presentation in relation to the given theme, and participants took part in three 20-min rounds of conversation. These conversations allowed for in-depth conversations around topics specific to participants and institutions. Further, the roundtable discussions provided an opportunity to share strengths of a particular curricular program (e.g., "Global Citizenship through University Partnerships" hosted by Roger Williams University) or talk through challenges (e.g., "Institutional Change \& Curricular Impact at University of Massachusetts - Boston"). These roundtables provided a relaxed forum to discuss successes and challenges, further contributing to the creation of a community of practice (Picture 2).

\section{Dine Arounds}

The Dine Arounds were casual dinners with groups of six to eight people at local restaurants on one evening of the symposium. At the dinners, participants took part in themed discussions hosted by a symposium organizer and/or local community developer. These optional, intimate gatherings provided opportunities to network with participants in smaller group settings and engage in the local community. Similar networking and relationship-building opportunities were also provided by a couple of informal happy hour receptions as part of the symposium. Here, participants followed-up on conversations from earlier in the day or inquired more about others' courses or institution, planting the seeds for a sustained community of educators.

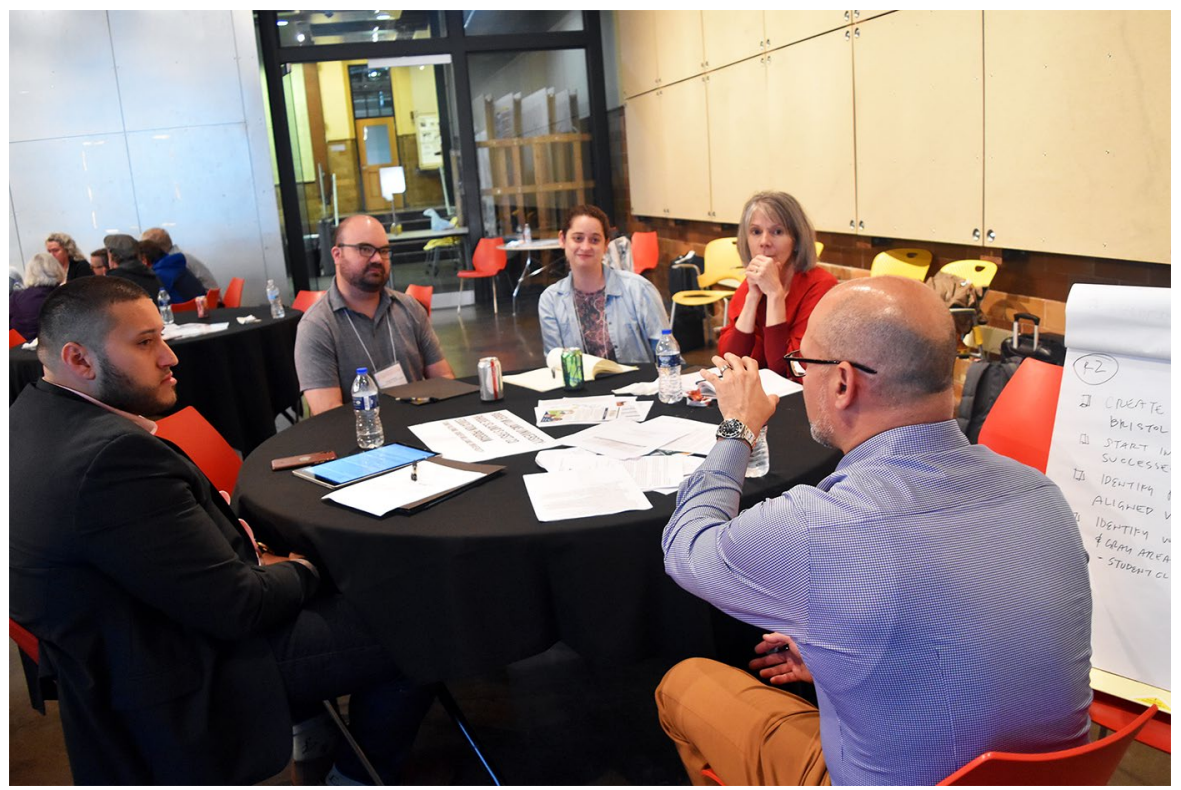

Picture 2 Participants Engaging during World Café Roundtables 


\section{Symposium Evaluation}

Upon conclusion of the symposium, 46 participants completed a paper version of the symposium evaluation questionnaire. The purpose of the evaluation was to describe the participants' perceptions of the outcomes, abilities developed, and benefits of the innovative symposium. The questionnaire consisted of two sections with quantitative rating scales, and one open-ended question.

Section one consisted of 15 Likert items that asked participants to rate their level of agreement or disagreement regarding the symposium's features and intended outcomes. A post-hoc reliability of the 15 items indicated the scale was reliable (Cronbach's alpha $=0.96$ ). A grand mean and standard deviation was reported for the 15 items and frequencies (percentages) were reported for individual items. Section 2 consisted of 10 items that asked participants to self-rate their level of abilities on various knowledge, skills, and dispositions community educators should have developed, both before (retrospectively) and after the symposium. Means and standard deviations were computed for each item to comparatively assess across the items. Post-hoc Cronbach alpha reliability coefficients were 0.90 for the retrospective pretest (before) and 0.84 for the post-test (after). Finally, participants were asked to answer an open-ended question about benefits of the symposium: "What aspect of the symposium was most beneficial to you?" There were 67 comments for the openended question because some participants provided more than one comment. The comments were sorted into descriptive categories based on initial codes. Similar codes were collapsed into categories and the count for the similar code was listed. Direct quotes from participants were used to increase credibility. Comments were reviewed by a panel of evaluation experts and peer debriefing and an audit trail was used to increase trustworthiness (Shenton, 2004). Assertions were made based on cross-cutting themes from the findings of three evaluation questions.

\section{Results}

\section{Participant Perceptions of Symposium Outcomes}

Regarding participant perceptions (see Table 1), participants' positively perceived the symposium generated desired outcomes $(M=4.08 ; S D=.73$; Table 1$)$. Nearly all the participants agreed the symposium engaged them to think critically about community development education (98\% agreed) and broadened their network with other colleagues in community development education (96\% agreed). Moreover, eight out of 10 participants agreed the symposium: (1) engaged them in meaningful dialogue with others from different disciplines/perspectives; (2) broadened their understandings of community development education; (3) created an interest to engage more in curriculum design; (4) motivated them to try innovative teaching strategies with my students; and (5) prompted them to implement a new idea they learned during the symposium in one or more of their courses. Two outcomes had less agreement. Seven out of 10 participants agreed the symposium created an interest to learn more about student inclusivity, and five out of 10 participants agreed 


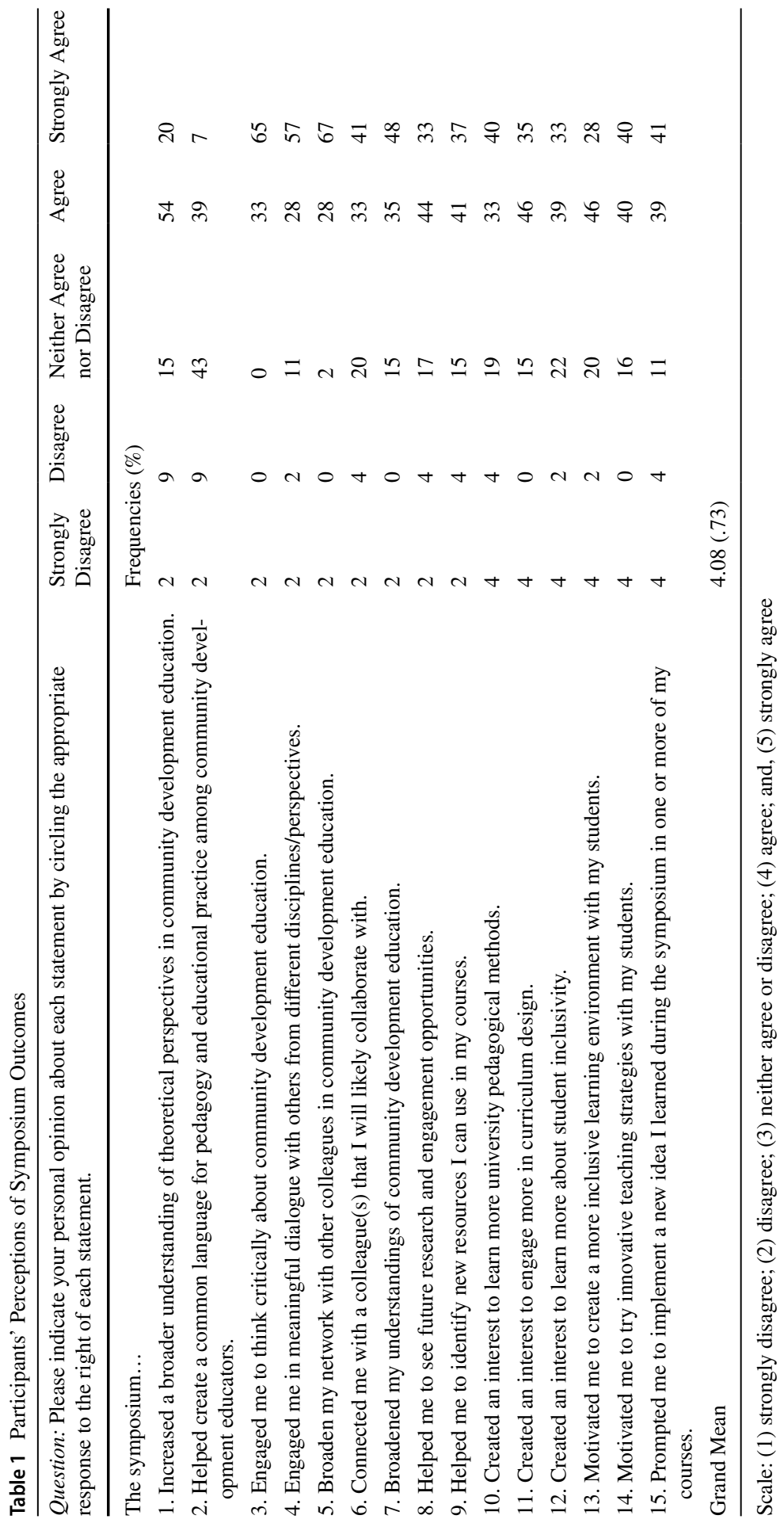


"the symposium helped create a common language for pedagogy and educational practice among community development educators."

\section{Participant Perceived Ability Level Regarding Knowledge, Skills, and Dispositions as Community Educators}

Regarding perceived ability level (see Table 2), participants perceived their levels of abilities regarding their knowledge, skills, and dispositions as community educators as $2.95(\mathrm{SD}=.77)$ before the symposium and $4.06(\mathrm{SD}=.47)$ after the symposium (Table 2). The self-reported increase for the participants had a large effect size $(d=1.74)$. Participants self-reported increases with large effect sizes for eight out of 10 abilities, and the abilities are listed in descending order based on effect sizes: (1) Having met \& networked with other professionals also undertaking CDE; (2) Having an awareness and knowledge of what's occurring in CDE programs across the United States; (3) Comprehending where the field of CDE has been and where it is going in the future; (4) Integrating innovative practices into my CDE-focused courses; (5) Assessing the role that CDE plays in higher education in the United States; (6) Appreciating the multidisciplinarity of the field of CDE; (7) Having a knowledge of university teaching pedagogies; and (8) Recognizing the essential role that culture can play in CDE. Participants self-reported an increase with a medium effect size for the ability, "Integrating theoretical perspectives into my CDE-focused courses." The ability with the least increase, "having cultural competence to effectively work with diverse audiences," had a small effect size $(\mathrm{d}=.49)$; although, it was close to being medium in size. Although this was the smallest increase, participants were in agreement that they were competent in working with diverse audiences.

\section{Participant Perspectives on Symposium Benefits}

Regarding participants' perspectives on the benefits of the symposium, participants reported the greatest benefits being the opportunity to build relationships with other community development educators and beginning to build a knowledge base of understanding the broader perspectives of community development education. There were 71 comments, which were coded and organized into seven categories: (1) meeting people; (2) networking and sharing ideas; (3) creating a sense of community; (4) broadening perspectives as a profession; (5) multi-interdisciplinary, interdisciplinary, and transdisciplinary focus; (6) engaging symposium format and venue; and (7) relevant topics.

\section{Meeting Colleagues}

Participants shared they benefited from meeting colleagues-new, smart, those interested in community development, people from different disciplines, and colleagues who use different pedagogies for community engagement. A couple quotes that represented this category were: "Meeting others thinking through this work 


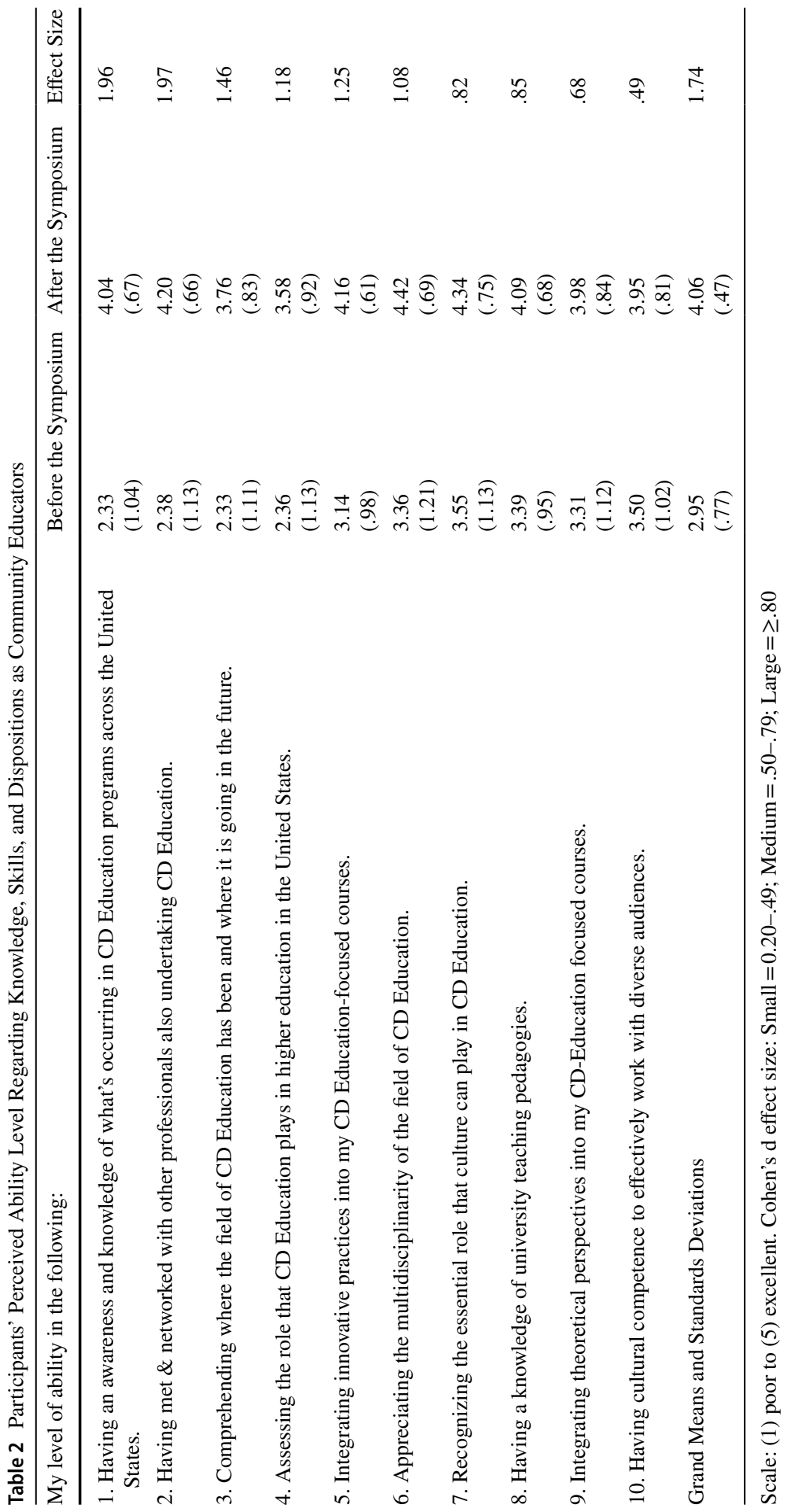


- new relationships and pedagogical approaches," and "meeting people from different disciplines and learning how they approach community engagement."

\section{Networking and Sharing Ideas with Colleagues}

Participants shared they benefited from networking and sharing ideas with colleagues. This category built on the previous category of meeting colleagues and focused on building social capital through networking and sharing ideas with colleagues; conversations during breaks, meals and outside the program; and learning what others are doing, including practitioners, professors and students. Participants shared they "broadened their professional networks" and "learned what others are doing." It is important to note the value participants found in learning from other participants outside of the formal symposium program (Picture 3).

\section{Building a Sense of Community}

Participants shared they benefited from the sense of community the symposium built. Participants described their sense of community using words such as listening, inclusive, respect, not alone, challenge to unify, being here, seeing the motivation of others, broadening their understanding of opportunities, and exploring collaborations. Participants shared, "the "community' feel with in this gathering of folks."

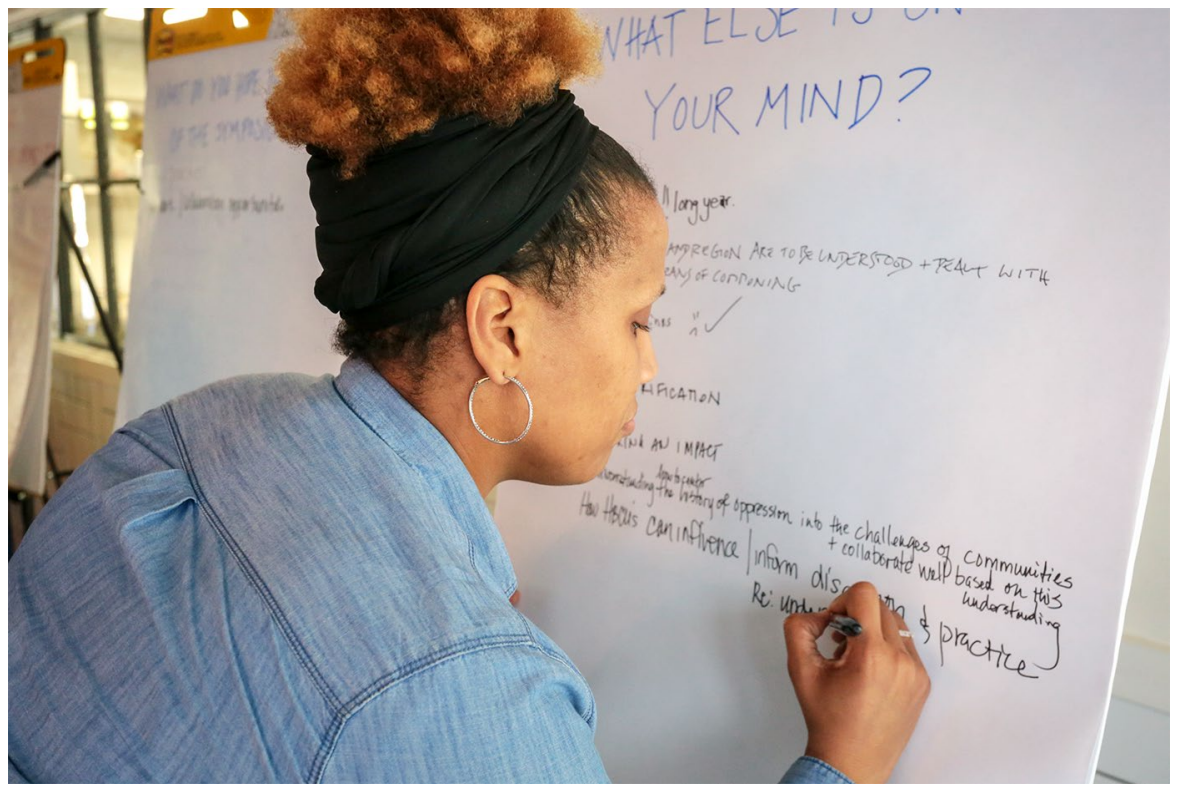

Picture 3 Participant Sharing Ideas on a Flip Chart during the Symposium 
Another participant added, "Understanding that we/our program is not alone - there are other CDE programs!" One participant summarized their thoughts, "I have benefitted in different ways - really enjoyed being here with members of my department to discuss opportunities to bring home new ideas, broadened sense of the different opportunities available to engage with colleagues from programs, greater sense of 'community' with community development educators [underlined by participant]."

\section{Broadening Perspectives of the Profession}

Participants shared they benefited from learning from colleagues who broadened their perspectives of the community development education profession. Participants used words to describe this category such as learning from colleagues; common issues, similarities, differences, challenges, and opportunities; what is and is not being addressed by CDE; beginning of a larger conversation; conversations about diversity, philosophical differences, critical theories, privilege, and serious issues; and the relationship between academic work and practice of community development. Participants shared some quotes including "to learn about common issues, challenges, and opportunities other community development programs face" and "I actually previously thought we were more similar, but we (CD programs) are perhaps not and maybe that's okay." One participant shared, "This symposium gave me a more concrete understanding of what is and is not being implemented in community development curriculum," whereas another participant benefited from "hearing a diversity of perspectives." Finally, a participant shared they benefited from "the real and tough conversations that we have engaged in."

\section{Multidisciplinary, Interdisciplinary, and Transdisciplinary Focus}

Participants shared they benefited from understanding the broadness and varieties of disciplines involved in community engagement. One participant shared, "The biggest take-away for me was the realization that community engagement is embedded in many disciplines." Participants commented that community development education can be multidisciplinary, interdisciplinary and transdisciplinary, especially the role service-learning pedagogy overlaps with CDE and how architecture and CDE can be transdisciplinary.

\section{Engaging Symposium Format, and Venue}

Participants shared the format, structure, and venue (i.e., Detroit) of the symposium had a variety of presentations, was well-facilitated and engaging, and enabled robust conversations with feedback from peers interested in similar research topics and community development projects. Although participants mentioned they enjoyed the lightning talks and the world café roundtables, some participants shared they would have liked additional time for more in-depth 


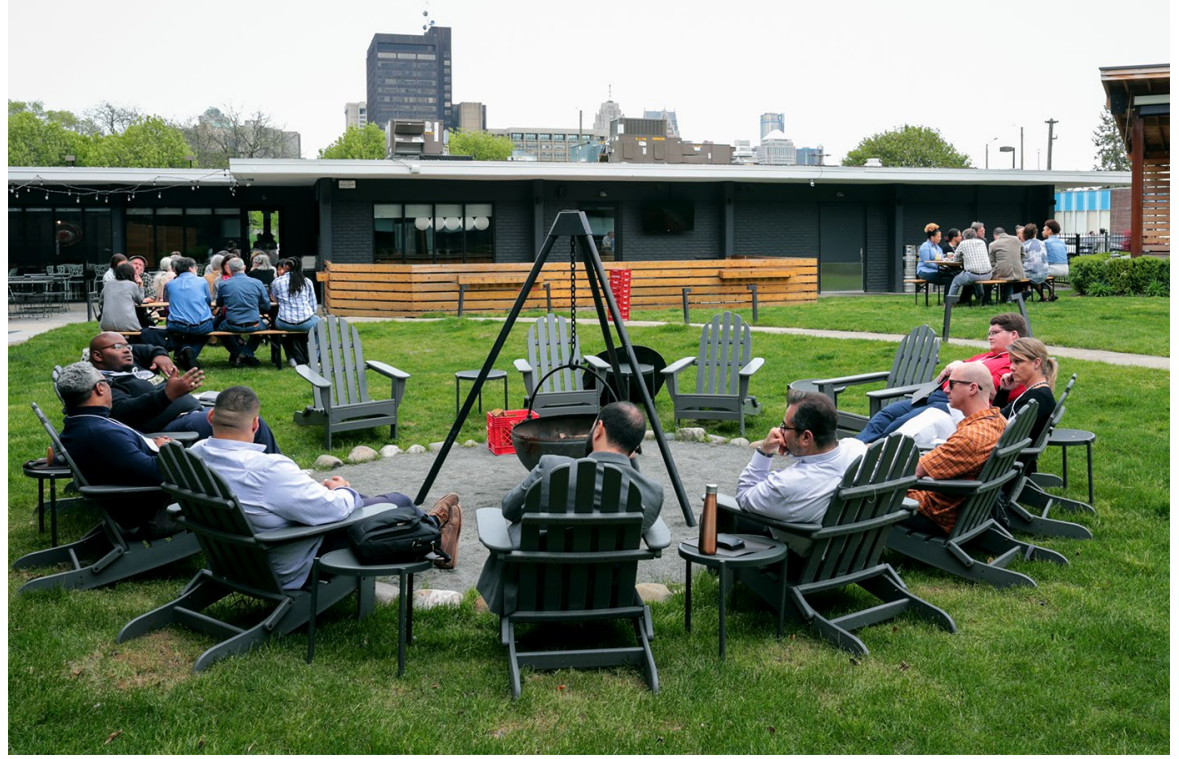

Picture 4 Participants Conversing during Story Circle Time at the Symposium

presentations. However, participants mentioned focused smaller discussion groups provided opportunities to "dive deep" and establish relationships with other faculty (Picture 4).

\section{Relevant Topics}

Participants mentioned learning specific topics from experienced people was beneficial. Specific topics mentioned were: (1) results from the Delphi study, including programs, curriculum, and teaching methods; (2) innovative pedagogies; (3) examples of bridging theory and practices for community development; (4) service learning; (5) Great Plains Alliance and online learning; (6) measuring depth and frequency of relationships; (7) grasping the importance of real estate finances; and (8) different perspectives (e.g., critical, art, and environmental).

\section{Discussion \& Recommendations}

Upon reflection, there were three primary themes discovered from the symposium evaluation. First, participants agreed the symposium format and venue were engaging and addressed relevant topics. Moreover, the symposium engaged community development educators to broaden their network, share ideas about best pedagogical practices, think critically and theoretically about community development education, and start a dialogue about the need for a cross-disciplinary, inclusive, and organized curriculum. Gruidl and Hustedde (2015) suggested that educators in U.S. 
post-secondary community development degree programs could be more effective across different contexts if they communicated with each other about the relevant theory, skill development, pedagogical approaches, and educational standards. Similar to the perspectives shared by Levy et al. (2016) and McCarthy et al. (2004), impactful participant engagement is one of the most important aspects of a good conference; even more salient is engaging professionals from a variety of fields and networks in order to build a stronger and more diverse cross-disciplinary group. The Community Development Education Symposium did just this, and as a result, a diverse group of community development higher education professionals connected and developed relationships.

Second, participants shared the symposium provided them the opportunity to grow and develop their pedagogical knowledge, skills, and dispositions as community development educators. Specifically, participants imparted they grew in their understanding of the current status and the trajectory of the community development education field, including its longitudinal impact on community well-being. Participants also shared they grew in their understanding of innovative practices, university teaching pedagogies, the role community development education plays in higher education, and the role of culture and theoretical perspectives in community development education. Clearly, participants felt they increased their human capital by participating in this symposium.

Third, participants shared the need for a community of practice as the collective benefit of the symposium. As such, the participants identified the importance of developing a strong network as community development educators to build relationships, share ideas, and create a sense of community. Participants also shared the symposium broadened their perspectives of career development education to be more focused on multidisciplinary, interdisciplinary, and transdisciplinary education. The symposium promoted networking (Deardorff, 2015) and a scholarly community (Rom, 2012), which can address the problem of CDE faculty being intellectually isolated. The customized conference approach (Rom, 2012) and unconference strategies (Hale \& Bessette, 2016) helped develop networking and a sense of community among faculty who are located across the U.S. in small departments and have limited professional interactions (Gruidl \& Hustedde, 2015). Although Castronova (2013) recommended an unconventional approach to conferences, the symposium balanced structure (Sawhney, 2013) and being participantdriven (Castronova, 2013). And finally, while we do not make causal claims, participants self-reported that panel discussions, speed talks, workshops, and social events encouraged engagement through sharing of information, experiences, and discussions (Korčulanin \& Meal, 2018).

Building upon this, the symposium also served as a conception point for the virtual Community Development Education Community of Practice $(\mathrm{CoP})$ that was established for community development educators after the symposium. Wenger et al. (2002) defined a CoP as a group of individuals who have a common goal and share knowledge with each other to better serve this goal. This encourages individuals to coalesce around a central issue of purpose and meaning for sharing knowledge within a group of people. The knowledge or practices that members share with the group then allows individuals of the group to 
become more proficient at serving the central issue, which in this case, is Community Development Education. The evolving Community Development Education $\mathrm{CoP}$ serves as a collaborative bringing together university-based instructors, students, and practitioners virtually to share their thoughts, works, and experiences through resources such as course syllabi, journal articles, activities, and best practices. Ultimately, developing a CoP associated with CDE within higher education is a good way to continue engaging professionals from diverse fields, further strengthening the professional community's solidarity and capacity and ultimately community well-being.

\section{Conclusions \& Recommendations}

Overall, the innovative processes of the Community Development Education Symposium were a rousing success supported by the quantitative and qualitative data presented. Participants loved the intimate, intense experience and felt they connected with others doing important community development education work across the United States. Designing an experience such as this was particularly useful in bringing together individuals in a multidisciplinary way. This novel symposium makes a strong case in several ways - utilizing this design for other groups desiring an intense, engaged experience; developing a broader set of convening goals to build community within the field, and utilizing unique and varied methods of sharing information.

Specifically, this experience could be useful in other situations where participants are connected by process, but hail from a variety of disciplinary areas, including diverse professional contributors associated with economic, social and psychological well-being of our communities (Phillips \& Lee, 2018). In addition, it could be especially important to explore equally compelling and innovative online symposium formats, given our new post-COVID reality. Clearly, this research supports the importance of face-to-face conferences or symposiums, but more research still needs to be done to determine how to develop an interest to learn more about inclusivity, develop cultural competence to advance diversity, equity and inclusion, and create a common language for pedagogy and educational practice among community development educators.

Finally, the symposium and correlating CoP provided a foundation to discuss pertinent issues facing community development education. For instance, how do faculty advocate CDE to administration? What are the best methods for student/community engagement? Should there be a core curriculum for community development programs nationally? If so, should there be an a accrediting body guiding the curriculum? These were just a few of the primary issues posed during the symposium that need deeper discussion and analysis and leaving one to ponder, what does an accrediting body and correlating curriculum look like for such a diverse multi-disciplinary field? Would it assist in advocating for our academic programs or would it limit the flexibility needed to do engaged work? These discussions pose a need for future symposiums and CoP platforms for discussions and research that continues to shape the field. 
Authors' Contributions Not applicable.

Data Availability Not applicable.

Code Availability Not applicable.

\section{Declarations}

Ethics Approval Not applicable.

Consent to Participate Not applicable.

Consent for Publication Individuals highlighted in the included photos have signed a Photo Consent form - allowing for publication of their images in a journal article. The authors can forward this in the future, if necessary.

Conflicts of Interest/Competing Interests Not applicable.

\section{References}

Castronova, E. (2013). Down with dullness: Gaming the academic conference. The Information Society, 29(2), 66-70. https://doi.org/10.1080/01972243.2012.757262.

Deardorff, M. (2015). Reconsidering the scholarly conference for the contemporary academic. PS: Political Science \& Politics, 48(2), 315-318. https://doi.org/10.1017/S1049096514002248.

Gruidl, J., \& Hustedde, R. (2015). Towards a robust democracy: The core competencies critical to community developers. Community Development, 46(3), 279-293. https://doi.org/10.1080/15575330. 2015.1028082.

Hains, K., Rios, M., Hains, B., Koundinya, V., Abrams, C., \& Stanard, V. (2021). An exploration of community development higher education in the United States: A programmatic study. Community Development, 52(1), 1-15. https://doi.org/10.1080/15575330.2021.1874457.

Hale, E., \& Bessette, L. S. (2016). New frontiers: Exploring the power and possibilities of the unconference as a transformative approach to faculty development. The Journal of Faculty Development, 30(2), 9-15.

Klentzin, J. C., Paladino, E. B., Johnston, B., \& Devine, C. (2010). Pecha Kucha: Using "lightning talk" in university instruction. Reference Services Review, 38(1), 158-167. https://doi.org/10.1108/00907 321011020798.

Korčulanin, L., \& Meal, V. R. (2018). Anthropologists and designers co-designing the future: Report on the sixth international applied anthropology symposium in Lisbon. Anthropology in Action, 25(3), 50-54. https://doi.org/10.3167/aia.2018.250306.

Kraeger, P., Cloutier, S. \& Talmage, C. (2017). Conclusions from the editors. In P. Kraeger, S. Cloutier \& C. Talmage (Eds.) New dimensions in community well-being (pp.255-260). Springer.

Lee, S. J., Kim, Y. \& Phillips, R. (2015). Exploring the intersection of community well-being and community development. In S. J. Lee, Y. Kim \& R. Phillips (Eds.) Community well-being and community development conceptions and applications (pp.1-8). Springer.

Levy, M., Hadar, I., Te'eni, D., Unkelos-Shpigel, N., Sherman, S., \& Harel, N. (2016). Social networking in an academic conference context: Insights from a case study. Information Technology \& People, 29(1), 51-68. https://doi.org/10.1108/ITP-09-2014-0220.

McCarthy, J. F., McDonald, D. W., Soroczak, S., Nguyen, D. H., \& Rashid, A. M. (2004). Augmenting the social space of an academic conference. Proceedings of the 2004 ACM Conference on Computer Supported Cooperative Work. ACM Press.

Phillips, R., \& Lee, S. J. (2018). Introduction to the inaugural issue of the international journal of community well-being. International Journal of Community Well-Being, 1, 1-2. https://doi.org/10.1007/ s42413-018-0009-x. 
Rom, M. (2012). The scholarly conference: Do we want democracy and markets or authority and tradition? Journal of Political Science Education, 8(4), 333-351. https://doi.org/10.1080/15512169. 2012.729449 .

Sawhney, H. (2013). Analytics of organized spontaneity: Rethinking participant selection, interaction format, and milieu for academic forums. The Information Society, 29(2), 78-87. https://doi.org/10. 1080/01972243.2013.758470.

Shenton, A. (2004). Strategies for ensuring trustworthiness in qualitative research projects. Education for Information, 22, 63-75. https://doi.org/10.3233/EFI-2004-2220.

United States Department of Agriculture (2014). Strategic Plan FY2014-2018. http://www.usda.gov/ documents/usda-strategic-plan-fy-2014-2018.pdf.

Wenger, E., McDermott, R. A., \& Snyder, W. (2002). Cultivating communities of practice: A guide to managing knowledge. Harvard Business School Press.

Wiseman, J., \& Brasher, K. (2008). Community wellbeing in an unwell world: Trends, challenges, and possibilities. Journal of Public Health Policy, 29, 353-366. https://doi.org/10.1057/jphp.2008.16.

Working Narratives. (n.d.). https://workingnarratives.org. Accessed 15 Mar 2020.

Publisher's Note Springer Nature remains neutral with regard to jurisdictional claims in published maps and institutional affiliations.

\section{Authors and Affiliations}

\section{Virginia Stanard ${ }^{1} \cdot$ Kristina D. Hains $^{2}$ (1) - Neil A. Knobloch ${ }^{3} \cdot$ Ceara O'Leary $^{1}$. Addie Reinhard ${ }^{4} \cdot$ Bryan J. Hains $^{2} \cdot$ Michael Rios $^{5}$}

1 University of Detroit Mercy School of Architecture, Detroit, MI 48221, USA

2 Community \& Leadership Development, Community Innovation Laboratory, University of Kentucky, Lexington, KY 40546, USA

3 Department of Agricultural Sciences, Education \& Communication, Purdue University, West Lafayette, IN 47907, USA

4 Department of Community \& Leadership Development, University of Kentucky, Lexington, KY 40546, USA

5 Department of Human Ecology, University of California, Davis, CA 95616, USA 